\title{
Formulation, Optimization, and Characterization of Repaglinide Loaded Nanocrystal for Diabetes Therapy
}

\author{
Gajanan Shinde, ${ }^{1}$ Mitesh Patel, ${ }^{1}$ Manan Mehta, ${ }^{1}$ Rajesh Kesarla, ${ }^{1}$ and Ganesh Bangale ${ }^{2}$ \\ ${ }^{1}$ Parul Institute of Pharmacy, Limda, Vadodara, Gujarat, India \\ ${ }^{2}$ Government College of Pharmacy, Amravati, Maharashtra, India \\ Correspondence should be addressed to Gajanan Shinde; swa14aug@gmail.com
}

Received 19 August 2014; Revised 3 December 2014; Accepted 3 December 2014

Academic Editor: Changyang Gong

Copyright (c) 2015 Gajanan Shinde et al. This is an open access article distributed under the Creative Commons Attribution License, which permits unrestricted use, distribution, and reproduction in any medium, provided the original work is properly cited.

\begin{abstract}
The aim of the present investigation was to formulate and characterize nanocrystal formulation of Repaglinide for diabetes therapy. Formulation was done by high pressure homogenization. HPH pressure and cycles range were screened by preliminary batches (T1 and T2). 5, 8, and 10 cycles and 500 to 1500 bar pressure range had kept for further investigation. Taguchi design was used to optimize type of polymer, \% polymer concentration, number of cycles, and HPH pressure for nanocrystal formulation. Formulations were characterized for particle size, zeta potential, and in vitro drug release. Optimized formulation (NC 3) showed particle size of 187 $\mathrm{nm}$, zeta potential of $-29.4 \mathrm{mv}$, and \% drug release of $80.58 \%$ and it was used for further study. Data analysis proved significant effects of factors on responses. Polydispersity index (PDI) Analysis of optimized formulation were found to be 0.248. SEM showed nanocrystal aggregation of drug, may be due to water removal process. DSC showed slight change in crystallinity, may be due to the presence of PEG 4000. Stability study was carried out for 3 months. It indicated no significant change in particle size and zeta potential. However, further studies in higher animals and human being need to be performed before this formulation can be commercially exploited.
\end{abstract}

\section{Introduction $[1,2]$}

Diabetes is one of the major diseases. Diabetes is a chronic condition that is caused by the body's incapability to produce or effectively use its own insulin. Insulin is a hormone necessary to convert food into glucose, which the body needs for the energy. Without production of enough insulin, glucose level becomes so high. As a result, permanent damage of blood vessel can occur.

There are two types of diabetes [3]: (1) diabetes insipidus (DI) and (2) diabetes mellitus (DM); it is a disorder that is characterized by the excretion of large amounts of severely diluted urine and excessive thirst with reduction of fluid intake having no effect on the concentration of the urine. There are several types of diabetes mellitus. Diabetes mellitus (DM) is a group of metabolic disorder in that the person has high blood sugar, either because cells do not respond to the insulin that is produced by the body or body does not produce enough insulinIt has also several types of various symptoms of diabetes which are as follows: polyphagia, blurred vision, loss of weight, and polyuria. Repaglinide $[4,5]$ is antidiabetic drug in the class of medications known as meglitinides [6]. Repaglinide is used to treat type 2 diabetes. Repaglinide depresses blood glucose concentrations by stimulating the release of insulin from beta cells of pancreatic islet tissue. This is done by a selective ion channel mechanism. Repaglinide prevents adenosine triphosphate (ATP) potassium channels on the beta cell membrane and potassium efflux. The resultant depolarization and calcium influx induce insulin secretion. Repaglinide is oral antihyperglycemic agent in type II diabetes. Repaglinide is BCS class II drug and its oral bioavailability is $56 \%$. Repaglinide is incompletely absorbed from the gastrointestinal tract and has low oral bioavailability because of the poor solubility. So, an attempt was made to increase the solubility of Repaglinide while formulating nanocrystal. If one could be increase the solubility then may be the rapid absorption and enhance the bioavailability. Decreasing the particle size by formulating nanocrystal may increase the surface area. 
The aim here is to make a nanocrystal formulation using Taguchi design with variable process in the face of variation over have little or no control. The Taguchi method involves reducing the variation in a process through robust design of experiments. The overall objective of the method is to produce high quality product at low cost to the manufacturer.

Nanocrystals are crystals having size less than $1 \mu \mathrm{m}[7,8]$. As the particle size of a crystal is decreased to about $100 \mathrm{~nm}$, there is a drastic change in the properties of the material. The decreased size increases the surface area and solubility of drug and there is proportionate increase in the bioavailability of poorly soluble drugs.

Drug nanocrystals consist of a polymeric matrix and an incorporated drug. Drug nanocrystals do not consist of any matrix material. Nanocrystal formulations are particles made from drug. Typically, they are stabilized by surfactant or polymeric steric stabilizers. Hence, these particles possess a better drug loading in contrast to matrix nanoparticle consisting of polymeric matrix (polymeric nanoparticle) or lipid matrix (nanoemulsions, liposomes, and lipid nanoparticles [9]).

The high loading makes them very efficient in transporting drug to or into cells, reaching a sufficiently high therapeutic concentration for the pharmacological effect. The nanocrystals are prepared in a liquid dispersion medium; that is, the nanocrystals are suspended in liquid. There are various types of advantages $[8,10,11]$. If Increase the rate of absorption and bioavailability may be Reduction in required dose. There are many types [9-17] of prepared nanocrystals; here, we prepare nanocrystals by high pressure homogenization microfluidizer technology (IDD-P technology), pistongap homogenization in water (DissoCubes), and piston-gap homogenization in nonaqueous medium (nanopure technology).

\section{Materials and Method}

2.1. Materials Used in the Present Work. The Repaglinide drug was obtained as a gift sample from Torrent Research Center, Ahmedabad, Poloxamer 188 was obtained as a gift sample from Sigma Aldrich, Peg 4000 was obtained as a gift sample from Sisco Research Lab., Mumbai, and polyvinyl alcohol, acetone, concentration HCL, and water used were of analytical grade. Dialysis bag was used from HiMedia Labs, Mumbai.

\subsection{Method}

\subsubsection{Experimental Methods}

(1) Solubility Study [16]. An appropriate amount of Repaglinide was dissolved in a beaker by continuously adding the suitable solvents. The solvents screening was conducted in water, methanol, chloroform, and acetone. The solvents were added in a pipette in aliquots of $0.2 \mathrm{~mL}$ applying magnetic stirring until complete dissolution of drug. The solubility was calculated in $\mathrm{mg} / \mathrm{mL}$. Once an approximate solubility was found, the saturation solubility was determined, after which the mixture was stirred on a magnetic stirrer at $80 \mathrm{rpm}$ for
$24 \mathrm{hr}$ and then filtered, and the content of dissolved drug was analyzed spectrophotometrically at $243 \mathrm{~nm}$.

(2) Production of Nanocrystal Formulations. Nanocrystal formulations were prepared by high pressure homogenization. The optimum combination of four independent variables, such as type of polymer, \% polymer concentration, number of cycles, and pressure of HPH, were at three levels by Taguchi orthogonal experimental design to achieve optimum particle size, zeta potential, and in vitro drug release.

(3) High Pressure Homogenization Method. Repaglinide loaded nanocrystal was prepared by high pressure homogenization method. Stabilizer was dissolved in $50 \mathrm{~mL}$ of distilled water to obtain aqueous surfactant solution and drug is separately dissolved in acetone. Then, drug solution is added into aqueous surfactant solution under high speed homogenizer at $10,000 \mathrm{rpm}$ for $15 \mathrm{~min}$. to obtain coarse suspension. Then, this coarse suspension was subjected to high pressure homogenizer at varying pressures and cycles. Samples were withdrawn after the size reduction step for size distribution analysis. Then, this nanocrystal dispersion was lyophilized to obtain the nanocrystal.

\subsubsection{Evaluation Method}

(1) Drug Excipients Compatibility Study [11]. FTIR spectroscopy was carried out to further elucidate the interaction With Repaglinide polymer. Repaglinide and polymers were mixed with $\mathrm{KBr}$ and pressed (1 tone) into the pellets to carry out spectra by applying sufficient pressure with precaution to avoid moisture.

(2) Measurement of Particle Size [18-26]. Particle Size and size distribution of the particles in the formulation were determined with a zetasizer nanoseries ZS. The sample for particle size analysis was added to a small dispersion unit called a cuvette. Average values were calculated from three batches of each sample. The diameters reported were calculated using volume distribution.

(3) Zeta Potential [20]. Zeta potential of the formulation was determined with a zetasizer nanoseries ZS. The sample for particle size analysis was added to the small dispersion unit called a cuvette. Average values were calculated from three batches of each sample.

(4) In Vitro Drug Release [26]. Dialysis bag diffusion technique was used to study in vitro release of drug from the prepared nanocrystal formulation. The $5 \mathrm{~mL}$ of formulation was placed in the dialysis bag HiMedia, molecular weight cut off 110 Dalton, sealed, and immersed into a $250 \mathrm{~mL}$ beaker containing $200 \mathrm{~mL}$ of the release media $0.1 \mathrm{~N} \mathrm{HCl}$ which was maintained at $37 \pm 0.5^{\circ} \mathrm{C}$ (stirred at $500 \mathrm{rpm}$ ) on magnetic stirrer (Remi instruments, India). Aliquots of $5 \mathrm{~mL}$ were withdrawn at predetermined time intervals $(5,15,30$, $45,60,90,120,150$, and $180 \mathrm{~min}$ ) and immediately restored with the same volume of fresh media maintained at the same temperature. The drug was analyzed spectrophotometrically using $0.1 \mathrm{~N} \mathrm{HCl}$ as a blank. 
(5) Polydispersity Index [20-22]. PDI analysis of the formulation were determined with a zetasizer nanoseries ZS. The samples for PDI analysis were added to the small sample dispersion unit called as a cuvette. Average values were calculated from three batches of each sample.

(6) Scanning Electron Microscopy [11]. Scanning electron microscopy was used to check the morphological evaluation of drug nanocrystals. For SEM, the sample were glued and mounted on metal sample plate. The sample plate was gold plated with sputter coater using electrical potential of $2 \mathrm{kv}$ at $25 \mathrm{mv}$ for $10 \mathrm{~min}$. The samples were examined under scanning electron microscope.

(7) Stability Study of the Formulation. The stability study of the formulation was carried out using three different temperature conditions according to $\mathrm{ICH}$ stability guideline Q1A R2: $5^{\circ} \mathrm{C} \pm 3^{\circ} \mathrm{C}$ (refrigerator), $30^{\circ} \mathrm{C} \pm 2^{\circ} \mathrm{C} / 65 \% \pm 5 \%$ $\mathrm{RH}$ (Ambient conditions), and $40^{\circ} \mathrm{C} \pm 2^{\circ} \mathrm{C} / 75 \% \pm 5 \% \mathrm{RH}$ (Stability Chamber). The nanocrystal formulation was stored in sealed vials and physical stability of the nanocrystal formulation was evaluated after 3 months. The particle size and zeta potential were measured by the Malvern Zetasizer.

\section{Result and Discussion}

3.1. Solubility Study. Methanol gave the highest solubility for Repaglinide, but it is toxic for oral use so it is not used. Repaglinide was also soluble in acetone and chloroform so that acetone was selected as a vehicle acetone $70 \pm 1.5 \mathrm{mg} / \mathrm{mL}$.

3.2. Drug Excipient Compatibility. FTIR studies are performed as described in analytical method. To check drug excipient compatibility, FTIR is used. For different samples, spectra of FITR are given in Figures 1, 2, 3, 4 and 5.

\section{Production of Nanocrystal Formulations}

To formulate and optimize a dosage form, many different experimental designs are available. From that Taguchi orthogonal ED is taken because it is easy to understand.

4.1. Taguchi Orthogonal Experimental Design. The optimum combination of independent variables (Table 2) and their correspondence between real and orthogonal values were varied at three levels. A Taguchi orthogonal experimental design (Table 3) was used to investigate the influence of critical variables as per Table 1 .

\section{Optimization of Formulation}

The parameters for the optimization are as follows.

(1) Polydispersity Index. According to the procedure given in the experimental work, the Polydispersity Index was determined and data were observed as shown in Table 4 . The formulation having the PDI value nearer to 0.2 it revealed that formulation NC 3 is monodispersibility. Normal value of PDI

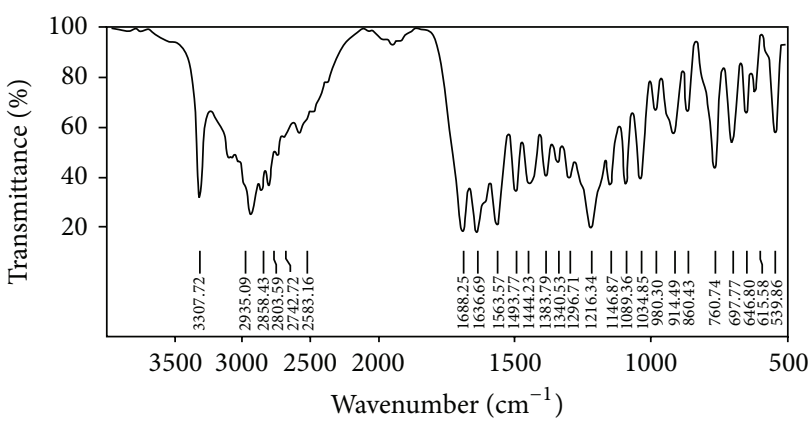

FIgURE 1: The infrared spectra of the drug.

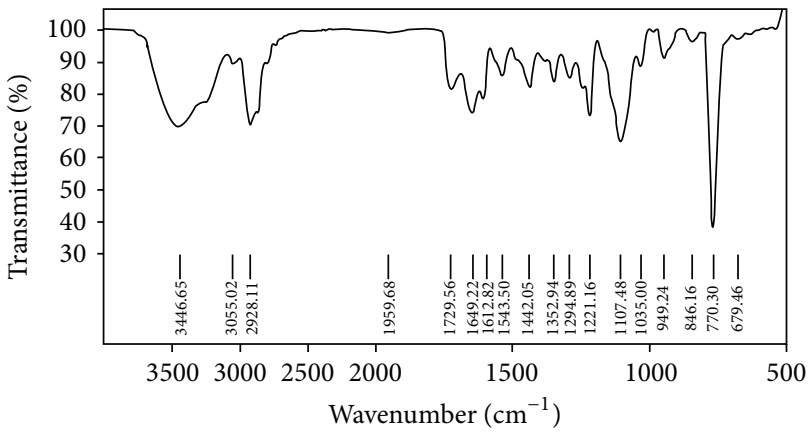

FIGURE 2: FTIR spectra of Repaglinide + PEG 4000.

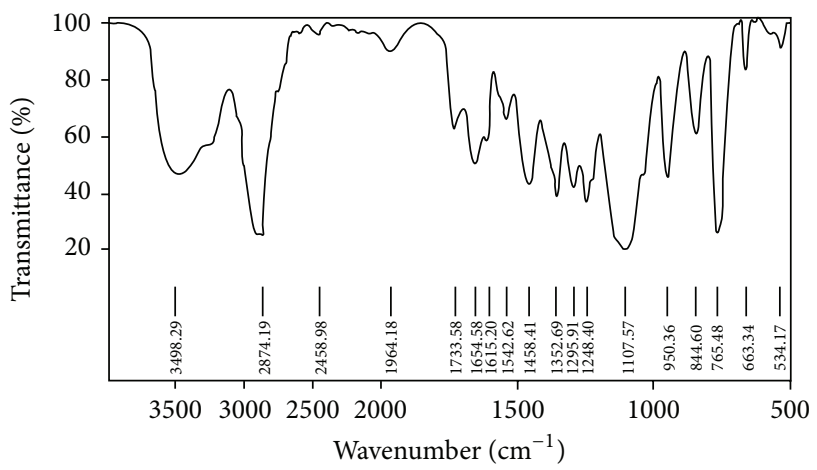

FIGURE 3: FTIR spectra of Repaglinide + pluronic F68.

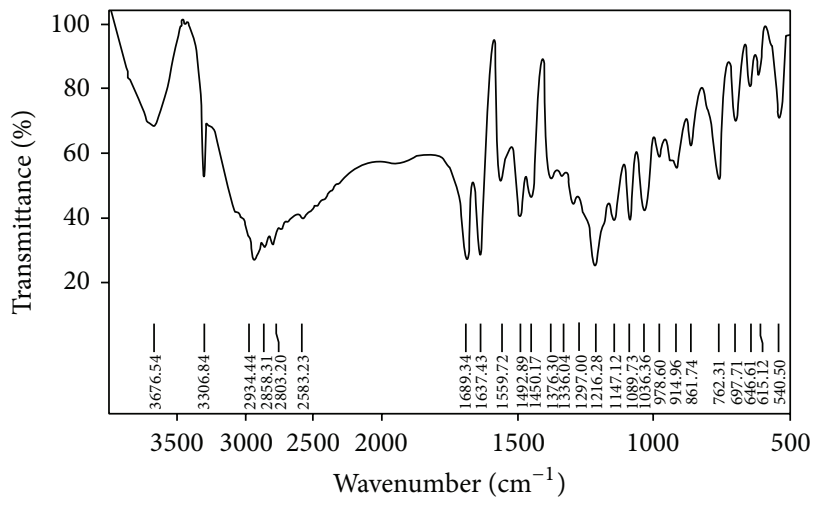

FIgURE 4: FTIR spectra of Repaglinide + PVA. 
TAble 1: General Taguchi experimental design.

\begin{tabular}{lllllllll}
\hline Experiment & 1 & 2 & 3 & 4 & 5 & 6 & 7 & 8 \\
\hline Independent variable & & & & & & & & \\
$A$ & 1 & 1 & 1 & 2 & 2 & 2 & 3 & 3 \\
$B$ & 1 & 2 & 3 & 1 & 2 & 3 & 1 & 3 \\
$C$ & 1 & 2 & 3 & 2 & 3 & 1 & 3 & 1 \\
$D$ & 1 & 2 & 3 & 3 & 1 & 2 & 2 & 3 \\
\hline
\end{tabular}

TABLE 2: Independent variables.

\begin{tabular}{lccc}
\hline Independent variable & \multicolumn{3}{c}{ Levels } \\
\hline A & 1 & 2 & 3 \\
$\quad$ Polymer & PEG 4000 & Poloxamer188 & PVA \\
$\begin{array}{l}\text { \% Polymer } \\
\quad \text { concentration }\end{array}$ & $0.75 \%$ & $1.5 \%$ & $2.25 \%$ \\
C Number of cycles & 5 & & \\
$\quad$ D & & & 15 \\
$\quad$ HPH pressure (BAR) & 500 & 1000 & 1500 \\
\hline
\end{tabular}

TABLE 3: Taguchi orthogonal experimental design.

\begin{tabular}{lcccc}
\hline Batch & $A$ & $B$ & $C$ & $D$ \\
\hline NC 1 & PEG-4000 & $0.75 \%$ & 5 & 500 \\
NC 2 & PEG-4000 & $1.5 \%$ & 8 & 1000 \\
NC 3 & PEG-4000 & $2.25 \%$ & 10 & 1500 \\
NC 4 & PLURONIC-F68 & $0.75 \%$ & 8 & 1500 \\
NC 5 & PLURONIC-F68 & $1.5 \%$ & 10 & 500 \\
NC 6 & PLURONIC-F68 & $2.25 \%$ & 5 & 1000 \\
NC 7 & PVA & $0.75 \%$ & 10 & 1000 \\
NC 8 & PVA & $1.5 \%$ & 5 & 1500 \\
NC 9 & PVA & $2.25 \%$ & 8 & 500 \\
\hline
\end{tabular}

is from 0.0 to 0.5 . The closer the PDI value to zero, the more homogeneous the particles.

(2) In Vitro Drug Release. In vitro drug release study was carried out as per the procedure given in the experimental work. The drug release data were obtained and were shown in Table 4 and the graph was shown in Figure 6. The maximum release study was obtained in formulation NC 3.

(3) Measurement of Particle. According to the procedure given in the experimental work, the particle size determination was carried out. Average particle size of each of the formulations is shown in the required size obtained in formulation batch NC 3 and all the batches failed to show the required particle size for the optimization. Particle size report of optimized formulation is as per Figure 7.

(4) Zeta Potential. Zeta potential of the resulting formulations was measured by Malvern Zetasizer. The high zeta value

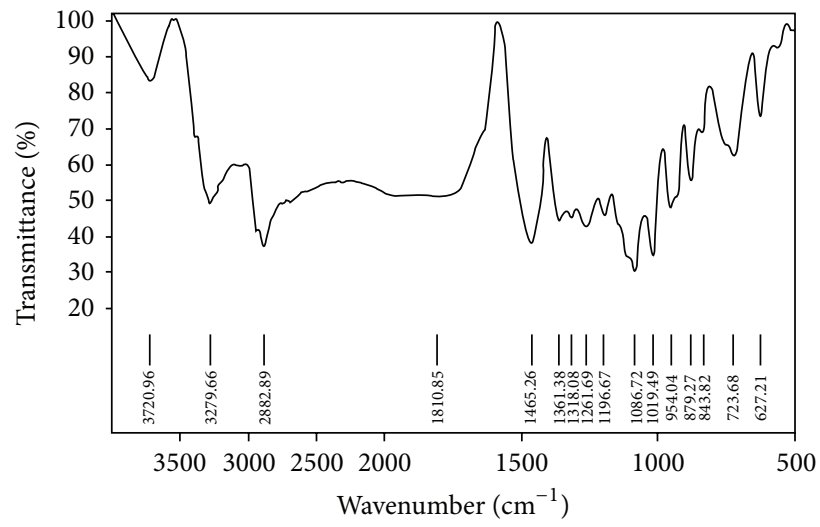

FIGURE 5: FTIR spectra of nanocrystals.

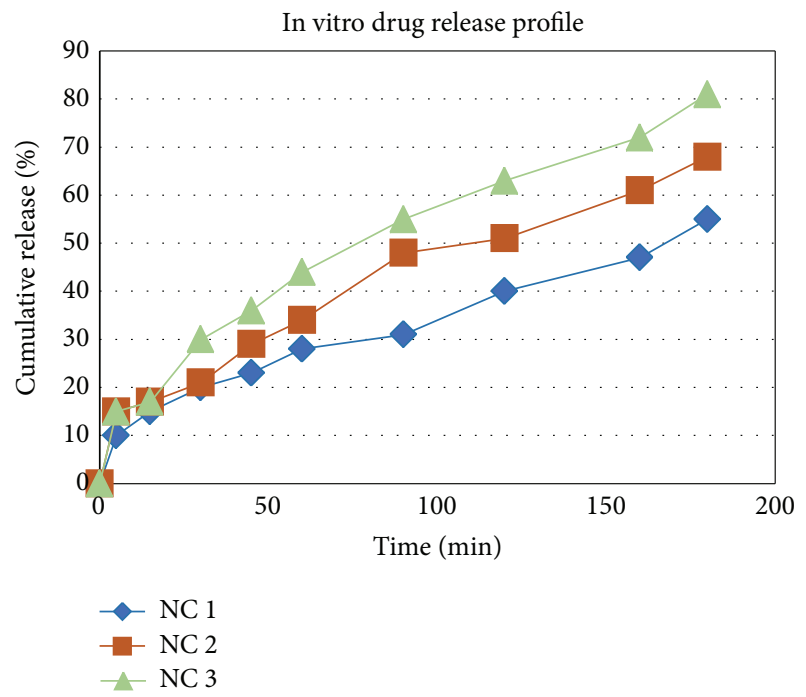

FIGURE 6: In vitro drug release profile.

indicates electrostatics repulsion between particles. The optimal batches NC 2 and NC 3 have zeta potential $-23.4 \mathrm{mv}$ and $-29.4 \mathrm{mv}$, respectively. But zetasizer result of optimized formulation is as per Figure 8.

(5) Stability Study of the Optimized Formulation. Particle size data of the nanocrystal formulation after production and after 3 months of storage are summarized in Table 5. Particle size and zeta potential were slightly affected by the temperature conditions. 
TABle 4: Measurement of \% entrapment efficiency, PDI, particle size, In vitro drug release, and zeta potential.

\begin{tabular}{|c|c|c|c|c|c|}
\hline \multirow[b]{2}{*}{ Sr. number } & \multicolumn{5}{|c|}{ Dependent variable } \\
\hline & Batch & $\begin{array}{c}\text { PDI } \\
(\text { Mean } \pm \mathrm{SD}), n=3\end{array}$ & $\begin{array}{l}\text { In vitro drug release study (\%) } \\
\quad(\text { Mean } \pm \mathrm{SD}), n=3\end{array}$ & $\begin{array}{l}\text { Particle size }(\mathrm{nm}) \\
(\text { Mean } \pm \mathrm{SD}), n=3\end{array}$ & $\begin{array}{l}\text { Zeta potential }(\mathrm{mv}) \\
(\text { Mean } \pm \mathrm{SD}), n=3\end{array}$ \\
\hline 1 & $\mathrm{NC} 1$ & $0.510 \pm 0.12$ & $55.38 \pm 1.25$ & $386.7 \pm 10.88$ & $-22.9 \pm 0.48$ \\
\hline 2 & $\mathrm{NC} 2$ & $0.267 \pm 0.06$ & $69.08 \pm 0.64$ & $213.5 \pm 8.68$ & $-23.4 \pm 1.22$ \\
\hline 3 & NC3 & $0.248 \pm 0.04$ & $80.58 \pm 1.71$ & $187 \pm 5.09$ & $-29.4 \pm 1.00$ \\
\hline 4 & NC 4 & $0.665 \pm 0.08$ & $59.64 \pm 1.1$ & $743.5 \pm 12.16$ & $-16.4 \pm 2.43$ \\
\hline 5 & NC 5 & $0.6 \pm 0.1$ & $65.33 \pm 1.41$ & $543.4 \pm 9.66$ & $-25.8 \pm 0.52$ \\
\hline 6 & NC 6 & $0.570 \pm 0.05$ & $78.26 \pm 2.08$ & $443.7 \pm 7.56$ & $-28 \pm 2.56$ \\
\hline 7 & NC 7 & $0.478 \pm 0.07$ & $32.88 \pm 0.98$ & $619 \pm 10.74$ & $-5.69 \pm 0.89$ \\
\hline 8 & NC 8 & $0.355 \pm 0.05$ & $44.69 \pm 1.21$ & $509.4 \pm 11.56$ & $-7.67 \pm 0.78$ \\
\hline 9 & NC 9 & $0.540 \pm 0.14$ & $52.71 \pm 1.29$ & $751 \pm 14.13$ & $-1.19 \pm 1.55$ \\
\hline
\end{tabular}

TABLE 5: Stability study of optimized formulation.

\begin{tabular}{lcc}
\hline $\begin{array}{l}\text { Stability study } \\
(\text { Mean } \pm \mathrm{SD})\end{array}$ & Particle size $(\mathrm{nm})$ & $\begin{array}{c}\text { Zeta potential }(\mathrm{mV}) \\
(\mathrm{Mean} \pm \mathrm{SD})\end{array}$ \\
\hline Starting formulation & $187 \pm 5.09-29.4 \pm 1.00$ & \\
After 3 months & $190 \pm 2.21-28.1 \pm 0.22$ & $-25.5 \pm 1.2$ \\
$5^{\circ} \mathrm{C} \pm 3^{\circ} \mathrm{C}$ (refrigerator) & $195.4 \pm 1.89$ \\
$30^{\circ} \mathrm{C} \pm 2^{\circ} \mathrm{C} / 65 \% \pm 5 \% \mathrm{RH}$ & & $-22.2 \pm 1.8$ \\
$\quad($ Ambient conditions) & $201.8 \pm 3.1$ & \\
$40^{\circ} \mathrm{C} \pm 2^{\circ} \mathrm{C} / 75 \% \pm 5 \% \mathrm{RH}$ & & \\
$($ Stability Chamber) & & \\
\hline
\end{tabular}

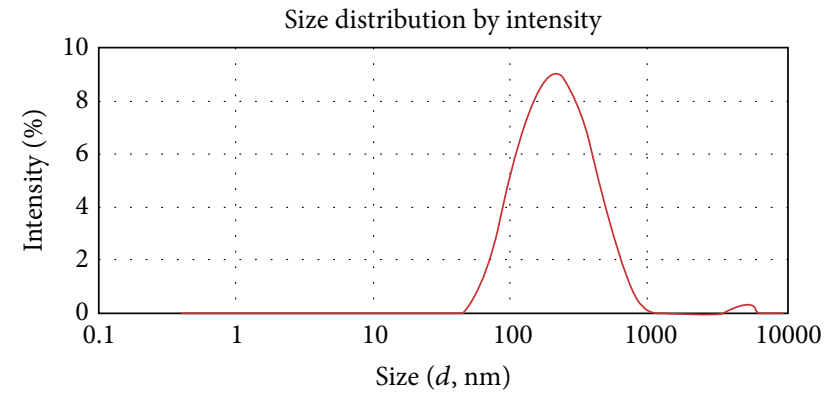

— Record 53: NC 6 D 1

FIGURE 7: Sample number: NC 3.

\section{Summary}

Repaglinide shows very low solubility and poor bioavailability. Considering the drawbacks of conventional dosage form, nanocrystal formulation was thought to provide required delivery. The main objective of this project was to develop a nanocrystal formulation for Repaglinide for the treatment of diabetes that is capable of efficient delivery of loaded drug. Nanocrystal formulation of Repaglinide will give the required release of drug through oral route. To achieve this objective, by using Taguchi experimental design, nanocrystal formulations of Repaglinide were prepared by high pressure homogenization method. While preparing it, the effect of various formulation variables like the type of polymer, \%

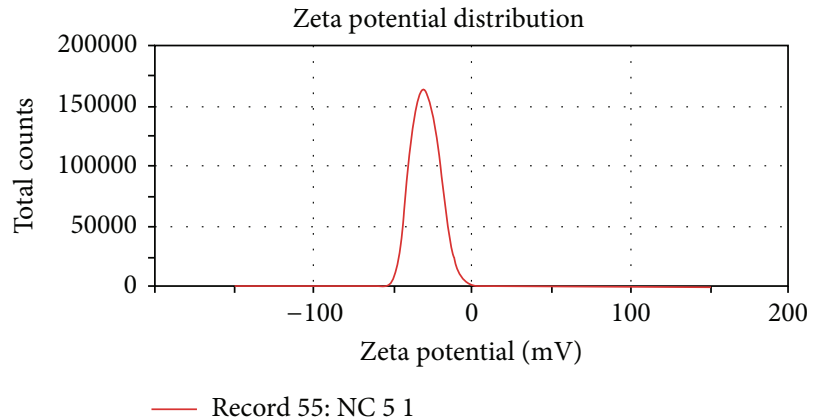

FIGURE 8: Sample number: NC 3.

polymer concentration, number of cycles, and high pressure homogenization pressure on the particle size, zeta potential, and in vitro drug release was evaluated. Optimized batch NC 3 was found to have the required particle size, zeta potential, and Polydispersity Index. Particle size of $187 \pm$ $5.09 \mathrm{~nm}$, zeta potential of $-29.4 \pm 1.00 \mathrm{mv}$, and PDI of $0.248 \pm$ 0.04 were obtained. Scanning electron microscopy (SEM) image of lyophilized formulation shows the formation of nanocrystalline drug particles. Nearly identical sharp melting point peak in DSC thermograms shows that there is slight physical change in crystalline form in the formulation which may be due to the presence of PEG 4000. Finally, stability studies were carried out at three conditions for 3 months. The final formulation was also examined for the particle size and zeta potential. The particle size of the optimized 
formulation was tested after 3 months and also zeta potential was determined in three different conditions. Results show that there is no more variation in particle size and zeta potential so the formulation is stable.

\section{Conclusion}

The present study was an attempt to formulate nanocrystals of poorly water soluble drug, Repaglinide, having low bioavailability. The objective was to increase the dissolution of drug and to improve the patient compliance. The nanocrystal formulation of Repaglinide with the smaller particle size can be effectively produced by the high pressure homogenization method. The nanosizing approach enhanced the in vitro drug release of the Repaglinide. Repaglinide was successfully entrapped within the polymer with high efficiency. Thus, nanocrystal approach may be a promising carrier for Repaglinide and other class II drugs.

\section{Conflict of Interests}

The authors declare that there is no conflict of interests regarding the publication of this paper.

\section{References}

[1] K. G. M. M. Alberti and P. Z. Zimmet, "Definition, diagnosis and classification of diabetes mellitus and its complications. Part 1: diagnosis and classification of diabetes mellitus. Provisional report of a WHO Consultation," Diabetic Medicine, vol. 15, no. 7, pp. 539-553, 1998.

[2] WHO Expert Committee on Diabetes Mellitus, "Second report," Technical Report Series 646, WHO, Geneva, Switzerland, 1980.

[3] American Diabetes Association, "Economic consequences of diabetes mellitus in the U.S. in 1997," Diabetes Care, vol. 21, no. 2, pp. 296-309, 1998.

[4] T. Abhinov, A. S. A. Khan, Ashrafa, S. Parveen, and K. P. Samapth Kumar, "Diabetes epidemic in India: risk factors, symptoms and treatment," Indian Journal of Research in Pharmacy and Biotechnology, vol. 1, no. 2, pp. 234-243, 2013.

[5] National Diabetes Data Group, "Classification and diagnosis of diabetes mellitus and other categories of glucose intolerance," Diabetes, vol. 28, no. 12, pp. 1039-1057, 1979.

[6] D. W. Cooke and L. Plotnick, "Type 1 diabetes mellitus in pediatrics," Pediatrics in Review, vol. 29, no. 11, pp. 374-385, 2008.

[7] R. H. Müller, S. Runge, V. Ravelli, W. Mehnert, A. F. Thünemann, and E. B. Souto, "Oral bioavailability of cyclosporine: solid lipid nanoparticles (SLN) versus drug nanocrystals," International Journal of Pharmaceutics, vol. 317, no. 1, pp. 82-89, 2006.

[8] E. Merisko-Liversidge, G. G. Liversidge, and E. R. Cooper, "Nanosizing: a formulation approach for poorly-water-soluble compounds," European Journal of Pharmaceutical Sciences, vol. 18, no. 2, pp. 113-120, 2003.

[9] G. Shinde, K. S. Rajesh, B. Devang, G. Bangale, D. Umalkar, and G. Virag, "Current status of colloidal system (nano range)," International Journal of Drug Formulation and Research, vol. 2, no. 6, pp. 39-54, 2011.
[10] J. Salazar, A. Ghanem, R. H. Müller, and J. P. Möschwitzer, "Nanocrystals: comparison of the size reduction effectiveness of a novel combinative method with conventional top-down approaches," European Journal of Pharmaceutics and Biopharmaceutics, vol. 81, no. 1, pp. 82-90, 2012.

[11] W. Sun, W. Tian, Y. Zhang, J. He, S. Mao, and L. Fang, "Effect of novel stabilizers-cationic polymers on the particle size and physical stability of poorly soluble drug nanocrystals," Nanomedicine: Nanotechnology, Biology, and Medicine, vol. 8, no. 4, pp. 460-467, 2012.

[12] J.-U. A. H. Junghanns and R. H. Müller, "Nanocrystal technology, drug delivery and clinical applications," International Journal of Nanomedicine, vol. 3, no. 3, pp. 295-309, 2008.

[13] E. Che, X. Zheng, C. Sun, D. Chang, T. Jiang, and S. Wang, "Drug nanocrystals: a state of the art formulation strategy for preparing the poorly water-soluble drugs," Asian Journal of Pharmaceutical Sciences, vol. 7, no. 2, pp. 85-95, 2012.

[14] H. Banavath, K. S. Raju, M. T. Ansari, M. S. Ali, and G. Pattnaik, "Nanosuspension: an attempt to enhance bioavailability of poorly soluble drugs," International Journal of Pharmaceutical Sciences and Research, vol. 1, no. 9, pp. 1-11, 2010.

[15] R. H. Müller and K. Peters, "Nanosuspensions for the formulation of poorly soluble drugs. I. Preparation by a size-reduction technique," International Journal of Pharmaceutics, vol. 160, no. 2, pp. 229-237, 1998.

[16] S. Katteboinaa, "Drug nanocrystals: a novel formulation approach for poorly solubledrugs," International Journal of PharmTech Research, vol. 1, no. 3, pp. 682-694, 2009.

[17] B. K. Nanjwade, G. K. Derkar, H. Bechra, and F. V. Manvi, "Nanosized technological approaches for the delivery of poorly water soluble drugs," Iranian Journal of Pharmaceutical Sciences, vol. 6, no. 3, pp. 149-162, 2010.

[18] J.-Y. Choi, J. Y. Yoo, H.-S. Kwak, B. U. Nam, and J. Lee, "Role of polymeric stabilizers for drug nanocrystal dispersions," Current Applied Physics, vol. 5, no. 5, pp. 472-474, 2005.

[19] Q. Fu, L. Kou, C. Gong et al., "Relationship between dissolution and bioavailability for nimodipine colloidal dispersions: the critical size in improving bioavailability," International Journal of Pharmaceutics, vol. 427, no. 2, pp. 358-364, 2012.

[20] J. Hecq, M. Deleers, D. Fanara, H. Vranckx, and K. Amighi, "Preparation and characterization of nanocrystals for solubility and dissolution rate enhancement of nifedipine," International Journal of Pharmaceutics, vol. 299, no. 1-2, pp. 167-177, 2005.

[21] R. Mauludin, R. H. Müller, and C. M. Keck, "Kinetic solubility and dissolution velocity of rutin nanocrystals," European Journal of Pharmaceutical Sciences, vol. 36, no. 4-5, pp. 502-510, 2009.

[22] P. Quan, K. Shi, H. Piao, N. Liang, D. Xia, and F. Cui, "A novel surface modified nitrendipine nanocrystals with enhancement of bioavailability and stability," International Journal of Pharmaceutics, vol. 430, no. 1-2, pp. 366-371, 2012.

[23] D. K. Krishna and H. P. Rajesh, "Dissolution enhancement of albendazole through nanocrystal formulation," Journal of Pharmacy and Bioallied Sciences, vol. 4, no. 5, pp. 62-63, 2012.

[24] F. Lai, E. Pini, G. Angioni et al., "Nanocrystals as tool to improve piroxicam dissolution rate in novel orally disintegrating tablets," European Journal of Pharmaceutics and Biopharmaceutics, vol. 79, no. 3, pp. 552-558, 2011.

[25] R. Mauludin, R. H. Müller, and C. M. Keck, "Development of an oral rutin nanocrystal formulation," International Journal of Pharmaceutics, vol. 370, no. 1-2, pp. 202-209, 2009. 
[26] N. G. Sahoo, M. Kakran, L. A. Shaal et al., "Preparation and characterization of quercetin nanocrystals," Journal of Pharmaceutical Sciences, vol. 100, no. 6, pp. 2379-2390, 2011. 

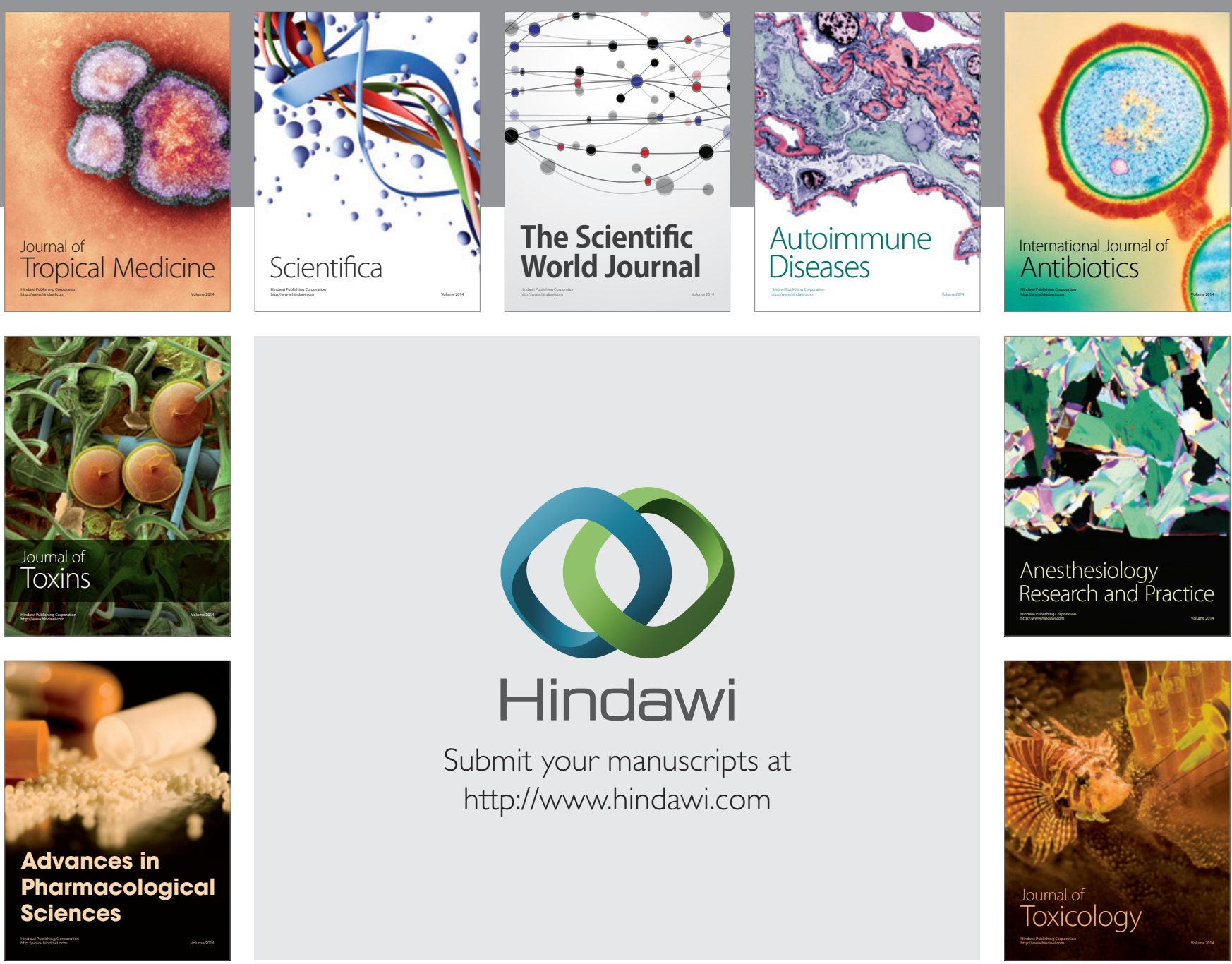

\section{Hindawi}

Submit your manuscripts at

http://www.hindawi.com
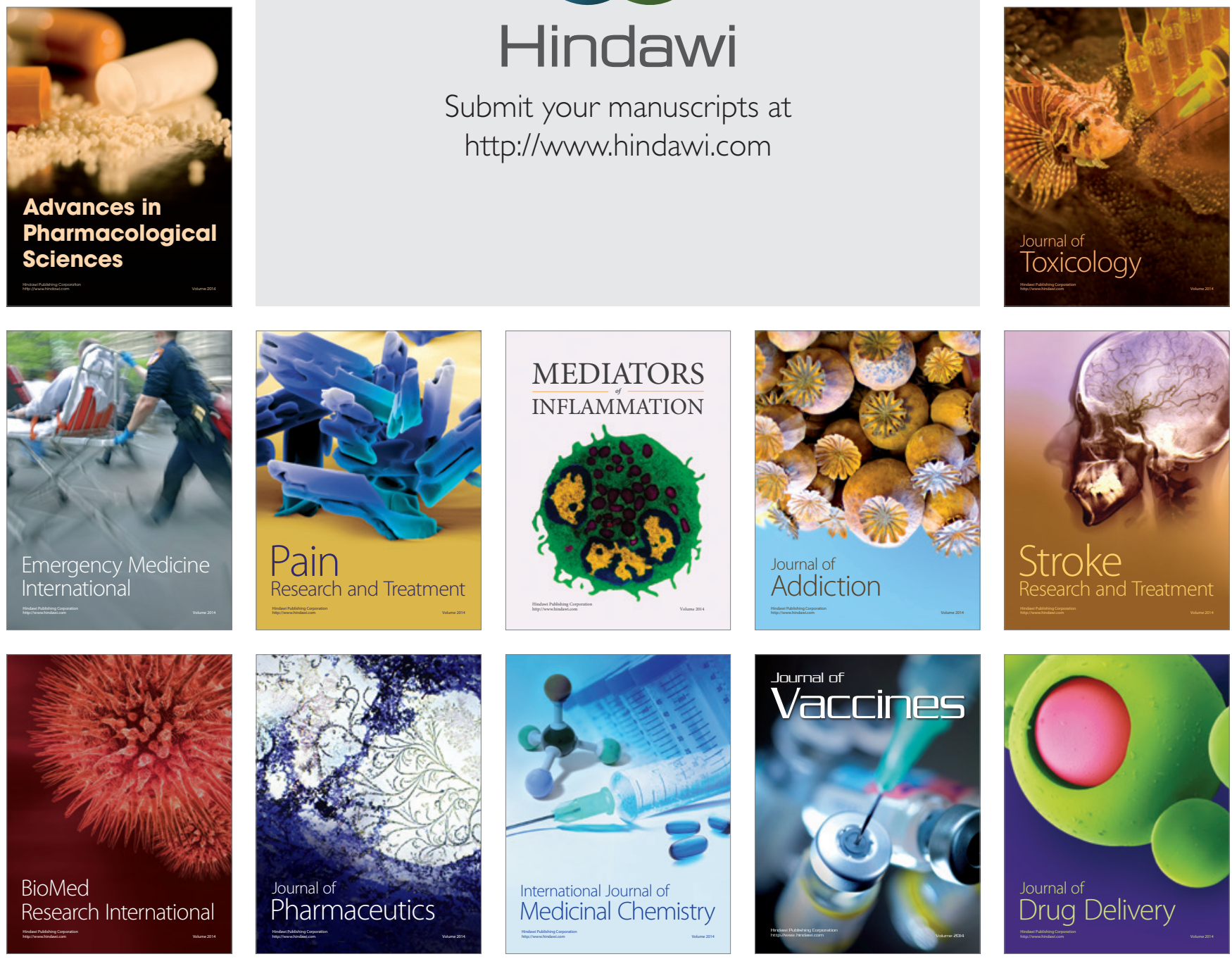